\title{
Toward a Learning Progression of Complex Systems Understanding
}

\author{
SUSAN A. YOON \\ University of Pennsylvania (USA) \\ SAO-EE GOH \\ Ministry of Education (Singapore) \\ ZHITONG YANG \\ Educational Technology Services (USA)
}

\begin{abstract}
Recent research on what students know about complex systems shows that they typically have challenges in understanding particular system ideas such as nonlinearity, complex causality, and decentralized control. Yet this research has yet to adopt a systematic approach to learning about complex systems in an ordered way in line with the Next Generation Science Standards' call for learning pathways that guide teaching and learning along a developmental continuum. In this paper, we propose that learning progressions research can provide a conceptual framework for identifying a learning pathway to complex systems understanding competence. As a first step in developing a progression, we articulate a sequence of complex systems ideas, from the least to most difficult, by analyzing students' written responses using an item response theory model. Results show that the easiest ideas to comprehend are those that relate to levels or scales within systems and the interconnected nature of systems. The most difficult ideas to grasp are those related to the decentralized organization of the system and the unpredictable or nondeterministic nature of effects. We discuss implications for this research in terms of developing curricular content that can guide learning experiences in grades 8-12 science education.
\end{abstract}

With the launch of the Next Generation Science Standards (NGSS) in 2013, arguably a new era of science education has been ushered in for $\mathrm{K}-12$ classrooms in the United States. As we translate the standards into curricular and instructional materials, it is prudent to take stock of the research on learning in particular scientific areas in order to build classroom experiences that can support knowledge development over time (National Research Council [NRC], 2007). This effort would 
also be in line with the focus on learning progressions in the NGSS. Among the crosscutting concepts in the NGSS, student learning challenges in understanding systems and system models constitute an area of science education research that has experienced recent growth. Crosscutting concepts are meant to connect canonical content domains such as biology and chemistry for which learning progressions have been proposed. However, we argue that content within a crosscutting concept can also be ordered in a learning progression to facilitate learning. Within the science education literature, learning about systems phenomena has most notably been anchored in the study of complex systems (Grotzer et al., 2015; Wilensky \& Rand, 2015; Yoon, 2011; Yoon, Goh, \& Park, 2018), which investigates how interactions between system components at lower scales give rise to higher scale processes and structures (Sweeney \& Sterman, 2007; Wilensky \& Reisman, 2006; Yoon, 2008). The way that schools of fish move through the water and herds of ungulates roam the savannah provide vivid examples of how individual actions and interactions lead to large-scale patterns.

A number of studies over the last 20 years have revealed challenges students have in learning about complex systems. We know, for example, that while students can identify relevant structural components, accurately describing causal behaviors of systems is more challenging (Hmelo-Silver, Marathe, \& Liu, 2007). Other studies have found that students have difficulties learning about scientific phenomena that emerge from nonlinear or nonsequential processes (Chi Roscoe, Slotta, Roy, \& Chase, 2012). Students also have difficulty understanding that control of processes in complex systems is often decentralized (Resnick, 1996; Yoon, 2008) and fail to see how system components are interconnected and interrelated (Ben-Zvi Assaraf \& Orion, 2010). Although several studies have promoted the learning of particular complex systems concepts (e.g., Klopfer et al., 2009; Levy \& Wilensky, 2009), we have yet to systematically determine a learning approach to address the learning challenges associated with complex systems in a comprehensive way (Hmelo-Silver \& Azevedo, 2006).

Learning progressions methodology offers one such systematic approach to structuring the learning of various complex systems ideas. Learning progressions are defined as sequences of ordered descriptions that illustrate the learning pathways students can take to improve conceptual competence in science (Alonzo \& Steedle, 2008 Consortium for Policy Research in Education [CPRE], 2009). For example, in biology, Mohan, Chen, and Anderson (2009) identified levels of increasing sophistication in students' perceptions of carbon-transforming events (e.g., combustion, respiration) in complex socio-ecological systems. These ordered descriptions represent a research-informed framework for structuring the learning of core scientific ideas (NRC, 2007, 2012). Curriculum and instructional activities can in turn be mapped onto the learning progressions to influence what, how, and when science concepts are learned throughout the learner's academic career (Gotwals \& Songer, 2010; Songer, Kelcey, \& Gotwals, 2009).

This study extends the research on learning progressions by focusing on complex systems ideas grounded in high school biology content. Our long-term goal is to design valid curricular and instructional activities based on a hypothesized learning progression of core structures and mechanisms found across complex systems. As a first step in the construction of a hypothesized learning progression, in this paper we report on exploratory work that investigates a conceptual sequence of complex systems ideas, from the least to the most difficult, by analyzing a diverse group of students' written responses to questions about a hypothetical ecological scenario. The 
following research question underpins this study: What concepts within the topic of complex systems do students find more or less challenging to understand?

\section{Theoretical Considerations}

The conceptual framework of this research lies at the intersection of what we know about how students reason about complex systems and what we know about learning progressions in science education. In the following sections, we first discuss known challenges in understanding complex systems before illustrating how considering a progression of sophistication of ideas as a methodology can help address these challenges.

\section{Understanding Complex Systems}

Students typically have misconceptions about complex systems (Ben-Zvi Assaraf \& Orion, 2005; Hmelo, Holton, \& Kolodner, 2000; Jacobson \& Wilensky, 2006). They tend to adopt a linear approach when thinking about the relationships among system components when in fact a nonlinear approach is warranted (Gotwals \& Songer, 2010; Hogan, 2000; Riess \& Mischo, 2010; Sweeney \& Sterman, 2007). That is, they incorrectly perceive single cause-and-effect relationships in which small actions lead to small effects. However, a complex system, with its multiple connections among components, can often result in an exponential action that gives rise to widespread effects at different system levels. Gotwals and Songer (2010), for example, found that students struggled with reasoning about how a disruption in one part of a food chain could affect a different part of the food chain that was not directly connected to the first part.

Grotzer and colleagues also found that students often reason about immediate effects rather than cascading or indirect effects. They fail to realize that a change in one population can have impacts on populations that are not directly linked through domino-like or cyclic complex causal relationships (Grotzer \& Basca, 2003; Grotzer et al., 2015). Grotzer and Tutwiler (2014) outlined a number of characteristics of complex systems that may contribute to these learning challenges. For example, some phenomena, such as climate change, occur across large spatial scales that involve distance between causes and effects. This makes covariation relationships difficult to understand because causes and effects exist in different attentional frames of the learner. Chi and colleagues (2012) similarly argue that major challenges in learning stem from students' difficulties in understanding complex causality and nonlinear dynamics. They state that students tend to understand and reason using direct-causal schema in which they attribute behaviors and outcomes to immediate one-to-one interactions, rather than reasoning with emergent schema that recognizes that the interconnected and web-like nature of systems will produce non-linear effects.

Other researchers have found that students generally incorrectly believe that systems are controlled by a central agent or component, and that systemic patterns are intentionally designed with predetermined functions (Penner, 2000; Resnick, 1996; Taber \& Garcia-Franco, 2010). In other words, students are unable to recognize that often control in systems is decentralized and that structures or behaviors at higher levels emerge from lower level system activities. For example, population trends of predators and prey in healthy ecosystems are able to stay in equilibrium because of the collective interactions of the predators and prey. The emergent nature 
of these lower level interactions between predators and prey manifests in the higher level state of equilibrium. Researchers argue that this attribution of centralized control and intentionality to system processes is due to students' inability to reason about how the scientific phenomenon in question functions or exists at different scales, such as at microscopic and macroscopic levels (Levy \& Wilensky, 2009, 2011; Wilensky \& Resnick, 1999).

In a series of studies Ben-Zvi Assaraf and colleagues have revealed that a common challenge for elementary and junior high school students is identifying components that comprise a system and understanding how those components are interrelated or exist as an integrated whole (Ben-Zvi Assaraf \& Orion, 2010; Ben-Zvi Assaraf \& Orpaz, 2010). Hmelo-Silver, Marathe, and Liu (2007) found that novices (middle school students and pre-service teachers) attend only to the superficial structural components of a system rather than the mechanisms that drive global system patterns that experts (biology researchers in their study) more easily recognize. Additionally, Wilkerson-Jerde and Wilensky (2015) found that the concept of nondeterminism or probablisitic behavior in systems is challenging for students to grasp.

Despite the valuable information these studies provide, they examine single aspects of complex systems understanding (e.g., nonlinearity, decentralized control, interrelatedness, and complex causality). From a learning progressions perspective, it is conceivable that some concepts are more challenging to learn than others. Several studies have already articulated analytical frameworks that encompass multiple complex systems ideas and beliefs (Hmelo-Silver \& Pfeffer, 2004; Hmelo-Silver et al., 2007; Jacobson, 2001; Jacobson, Kapur, So, \& Lee, 2011; Yoon, 2008, 2011). For example, Jacobson and his colleagues (2001) developed a framework that delineates distinct categories of complex systems ideas. Using this framework in an expert-novice study, he discovered that pre-college students tend to believe that systems operate in reductive, centralized, and predictable ways, whereas science experts describe phenomena as nonreductive, decentralized, and nonlinear. We adapt this framework and evolutions of it (Jacobson et al., 2011, Yoon, 2008, 2011) to analyze levels of understanding for various ideas of complex systems. In doing so, we unpack and reveal the relative levels of difficulties that can eventually inform the development of a learning progression.

\section{Learning Progressions}

Learning progressions provide a systematic approach to organizing curriculum and instructional activities that represent cognitive pathways and skills students are likely to follow over a period of time in mastering scientific concepts (Alonso \& Steedle, 2006; NRC, 2007). Learning progressions structure the sequences based on what cognitive researchers know about science learning from empirical research findings (CPRE, 2009). Research on learning progressions is still somewhat new to the field of education and more rigorously conducted studies to provide evidence of improved teaching and learning is needed (CPRE, 2009). However, the growing interest in learning progressions to support curriculum and instruction in science education is evidenced in the number of researchers in multiple educational scientific domains who are interested in advancing the state of the art (see Alonzo \& Gotwals, 2012 for a list of education researchers). Furthermore, while we acknowledge the need for testing the learning progressions that underpin the NGSS, the fact that these standards were based in a learning progressions pedagogy provides more support for their examination and use. However, the NGSS themselves, 
do not articulate a comprehensive list of complex systems ideas that should be sequenced in a progression. For the cross-cutting concept of Systems and System Models, the standards suggest the following levels of learning:

In grades K-2, students understand that objects and organisms can be described in terms of their parts and that systems in the natural and designed world have parts that work together.

In grades 3-5, students understand that a system is a group of related parts that make up a whole and can carry out functions its individual parts cannot. They can also describe a system in terms of its components and their interactions.

In grades 6-8, students understand that systems may interact with other systems; they may have sub-systems and be a part of larger complex system. They can use models to represent systems and their interactions-such as inputs, processes, and outputs-and energy, matter, and information flows within systems. They also learn that models are limited in that they only represent certain aspects of the system under study.

In grades 9-12, students investigate or analyze a system by defining its boundaries and initial conditions, as well as its inputs and outputs. They use models to simulate the flow of energy matter and interactions within and between systems at different scales. They also use models and simulations to predict the behavior of a system and recognize that these predictions have limited precision and reliability due to the assumptions and approximations inherent in the models. They also design systems to do specific tasks.

In these standards, the use of general language such as "inputs, processes, and outputs" does not provide teachers with an understanding of what entails an input, process, or output. Moreover, students should know how systems behave in order to be able to interpret models or simulations of complex phenomena. These system behaviors are not spelled out in the standards. Thus, although the present research is not, as yet, anchored in classroom practice, which is required for testing and validation (Shavelson \& Kurpius, 2012), this study represents important initial steps to hypothesize a learning progression, with details about central complex systems characteristics that represent the substance of what students should learn about complex systems.

To date, there have been three published works on learning progressions on biology topics related to complex systems concepts (Gotwals \& Songer, 2010; Mohan et al., 2009; Songer et al., 2009). These studies have collectively ascertained that students' learning of biological systems, or the development in the way they think about systems, follows a trajectory. However, these progressions address particular science content, such as ecosystems and biodiversity, rather than a more generalized complexity perspective. Ben-Zvi Assaraf and Orion $(2005,2010)$ have also examined students' development of systems thinking abilities. Although they have not characterized their work in terms of learning progressions, they have constructed a hierarchical 
model of the stages by which students reason about complex systems. They explain that at the most rudimentary level, students were able to identify the components of a system and processes within the system. At the intermediate level, students were able to identify relationships between system components, and could organize the systems' components, processes, and their interactions within a framework of relationships. At the most sophisticated level students could perceive hidden system components, make predictions about how the system evolves, and explain how current systems emerge in relation to its history. However, their stage model comprises a subset of essential complex systems components as identified in Jacobson (2001). A sequence, or markers, for learning about other equally salient ideas, such as decentralization and emergence, is also necessary to ensure that students acquire an adequate overall understanding.

To begin to develop a learning progression on complex systems concepts, researchers must first differentiate a comprehensive set of ideas in terms of greater or lesser difficulty. Such delineation can help organize the sequence of ideas to be learned. There are generally two broad approaches to constructing initial learning sequences (CPRE, 2009). The first approach begins by conjecturing a possible sequence from existing literature and then validating it. For example, Songer and colleagues (2009) first hypothesized their learning progression on biodiversity from literature reviews and then tested the validity of the progression by comparing student learning outcomes in a control-treatment study. The second approach starts by analyzing a cross-sectional sample of students' responses that provide indicators of their understanding and then derives the levels of sophistication or difficulty from the analysis. For instance, Mohan and colleagues (2009) first analyzed almost 300 upper elementary and high school students' written accounts of the biogeochemical processes of carbon cycling in socio-ecological systems for distinct levels of sophistication, and then constructed their progression based on these levels. The latter approach

presents an advantage when existing literature does not tell us much about which ideas and concepts should be learned before others. In our exploratory study, we adopt this more inductive approach in locating the initial sequence of a complex systems learning progression.

\section{Methods}

\section{Context and Participants}

This study was part of a larger research project funded by the US National Science Foundation. We designed and developed curriculum and instructional activities using computational modeling tools for high school biology content to promote student learning of complex systems. While these activities were being constructed and tested, we focused concurrently on building the learning progression that informed them. To begin with, we developed eight open-ended, short-answer questions, so that we had two such questions for each of four biology units that were part of the larger study. These questions were developed by PhD-level biology content experts, while others were selected from the OECD Programme for International Student Assessment (PISA; 2006). We wanted to administer this test to students in grades 8 to 12 who had already learned some biology content in order to determine the range of conceptual difficulties.

To recruit students to participate in our study, we enlisted the support of science teachers with whom we had previously worked in another study. We targeted different kinds of schools 
(including magnet, public, and charter) to account for differences in science learning experience, and asked teachers to nominate generally moderate- to high-achieving students. All students were recruited from a large urban school district in the northeastern United States. Two days prior to the implementation, a researcher went to the teachers' classes and gave a short presentation on the goals of the study and the roles of the students (should they agree to participate). Those who participated were initially encouraged by their teachers to take part in the study but were ultimately self-selected. Their involvement lasted about 1 hour after school, during which they answered open-ended questions on the biology test. The students were given as much time as they required to answer the questions. In total 44 students of various ethnicities participated in the study. There were 20 males and 24 females in grades 8 (5 students), 9 (13 students), 10 (14 students), and 12 (12 students). Recruitment and data collection occurred over 3 months.

\section{Data Sources, Coding, and Analyses}

For this paper, we present the analysis of student responses to the following question:

Imagine a flock of geese arriving in a park in [your city], where geese haven't lived before. Describe how the addition of these geese to the park affects the ecosystem over time.

Consider both the living and non-living parts of the ecosystem.

This question, written by an expert in biology, sought to elicit students' understanding of biology and complex systems in an ecological context.

A content analysis of the students' responses was performed using six categories of complex systems understanding - predictability of effects, scaling effects, networked interactions, multiple causes, order, and dynamic processes - derived from Jacobson's (2001; Jacobson et al., 2011) and Yoon's $(2008,2011)$ studies. Table 1 provides more details of the coding scheme used in the content analysis. To account for variation in students' understanding of the complexity ideas, responses were coded six times (once for each category) for four levels of increasing sophistication: Completely Clockwork (Level 1), Somewhat Clockwork (Level 2), Somewhat Complex (Level 3), and Completely Complex (Level 4). Clockwork responses are those that show deterministic, linear, single-cause, non-networked, centralized, or static system interactions or states, whereas complex responses are those that demonstrate nondeterministic, nonlinear, multiple causes, networked, decentralized, or dynamic system interactions or states. These categories were derived from a literature review of core complex systems characteristics identified in scientific studies and presented in Jacobson (2001). Yoon (2008) subsequently parsed the categories into four levels of understanding to determine whether students' ideas improved over time in a curricular intervention. The categories and levels have been further validated in other studies (Jacobson, 2011; Yoon, 2011) to demonstrate both the salient nature of these ideas as core complex systems content and growth in the levels of understanding students are able to achieve after instruction.

After the coding manual was constructed and vetted, its reliability was assessed with two independent doctoral student raters coding $20 \%$ of the written responses. An acceptable inter-rater agreement of 0.8 was achieved collectively across categories using the Cronbach 
alpha reliability test. The remainder of the responses were subsequently coded by the first two authors using the coding scheme, with any discrepancies discussed.

Table 1

Complex Systems Category Code Descriptions

\begin{tabular}{|c|c|c|c|c|}
\hline Category & $\begin{array}{l}\text { Completely } \\
\text { clockwork (Level } \\
\text { 1) }\end{array}$ & $\begin{array}{l}\text { Somewhat } \\
\text { clockwork (Level } \\
\text { 2) }\end{array}$ & $\begin{array}{l}\text { Somewhat } \\
\text { complex (Level } \\
\text { 3) }\end{array}$ & $\begin{array}{l}\text { Completely } \\
\text { complex (Level 4) }\end{array}$ \\
\hline $\begin{array}{l}\text { Deterministic } \\
\text { effects } \\
\text { The emphasis is } \\
\text { the } \\
\text { predictability of } \\
\text { the effects } \\
\text { caused by the } \\
\text { variable in } \\
\text { question. }\end{array}$ & $\begin{array}{l}\text { Response shows } \\
\text { that the way in } \\
\text { which a variable } \\
\text { operates or affects } \\
\text { other variables is } \\
\text { completely } \\
\text { predictable or } \\
\text { deterministic. No } \\
\text { alternative is } \\
\text { offered in the } \\
\text { response. }\end{array}$ & $\begin{array}{l}\text { Response shows } \\
\text { that the way in } \\
\text { which a variable } \\
\text { operates or affects } \\
\text { other variables is } \\
\text { somewhat } \\
\text { predictable or } \\
\text { deterministic. } \\
\text { There are 1-2 } \\
\text { possibilities } \\
\text { suggested in the } \\
\text { response. }\end{array}$ & $\begin{array}{l}\text { Response shows } \\
\text { that the way in } \\
\text { which a variable } \\
\text { operates or } \\
\text { affects other } \\
\text { variables is } \\
\text { somewhat } \\
\text { unpredictable or } \\
\text { nondeterministic. } \\
\text { There are 3-4 } \\
\text { possibilities } \\
\text { suggested in the } \\
\text { response. }\end{array}$ & $\begin{array}{l}\text { Response shows } \\
\text { that the way in } \\
\text { which a variable } \\
\text { operates or affects } \\
\text { other variables is } \\
\text { unpredictable or } \\
\text { nondeterministic. } \\
\text { There are many } \\
\text { possibilities } \\
\text { suggested in the } \\
\text { response and that } \\
\text { patterns might } \\
\text { emerge over time. }\end{array}$ \\
\hline $\begin{array}{l}\text { Scaling effects } \\
\text { Three } \\
\text { components are } \\
\text { considered: (i) } \\
\text { the relative scale } \\
\text { of outcomes } \\
\text { caused by } \\
\text { action; (ii) the } \\
\text { cascading effects } \\
\text { or } 2^{\text {nd }} \text { order } \\
\text { impacts or } \\
\text { ripple effects of } \\
\text { the action; and } \\
\text { (iii) the time } \\
\text { scale at which } \\
\text { changes happen. }\end{array}$ & $\begin{array}{l}\text { Response indicates } \\
\text { (i) small actions } \\
\text { only lead to small } \\
\text { effects; (ii) there is } \\
\text { a sense that the } \\
\text { action causes } \\
\text { localized changes } \\
\text { only; and (iii) the } \\
\text { changes are } \\
\text { immediate and do } \\
\text { not sustain for a } \\
\text { long time. }\end{array}$ & $\begin{array}{l}\text { Response contains } \\
\text { one complex } \\
\text { component (out of } \\
\text { three) of the } \\
\text { scaling effects. } \\
\text { (See Level } 4 \text { ) }\end{array}$ & $\begin{array}{l}\text { Response } \\
\text { contains two } \\
\text { complex } \\
\text { components (out } \\
\text { of three) of the } \\
\text { scaling effects. } \\
\text { (See Level 4) }\end{array}$ & $\begin{array}{l}\text { Response } \\
\text { indicates (i) small } \\
\text { actions can lead to } \\
\text { large effects; (ii) } \\
\text { the action can } \\
\text { produce both } \\
\text { localized changes } \\
\text { (one-to-one) and } \\
\text { cascading (ripple) } \\
\text { effects; and (iii) } \\
\text { the changes can } \\
\text { take place both } \\
\text { immediately and } \\
\text { over a long period } \\
\text { of time. }\end{array}$ \\
\hline $\begin{array}{l}\text { Multiple causes } \\
\text { The focus is on } \\
\text { the number of } \\
\text { causes that } \\
\text { may/will } \\
\text { contribute to the } \\
\text { outcome(s) of an } \\
\text { event. }\end{array}$ & $\begin{array}{l}\text { Response } \\
\text { attributes the } \\
\text { outcome(s) of an } \\
\text { event to one } \\
\text { cause/factor. }\end{array}$ & $\begin{array}{l}\text { Response } \\
\text { attributes the } \\
\text { outcome(s) of an } \\
\text { event to two } \\
\text { causes/factors. }\end{array}$ & $\begin{array}{l}\text { Response } \\
\text { attributes the } \\
\text { outcome(s) of an } \\
\text { event to three } \\
\text { causes/factors. }\end{array}$ & $\begin{array}{l}\text { Response } \\
\text { attributes the } \\
\text { outcome(s) of an } \\
\text { event to four or } \\
\text { more } \\
\text { causes/factors. }\end{array}$ \\
\hline
\end{tabular}




\begin{tabular}{|c|c|c|c|c|}
\hline $\begin{array}{l}\text { Networked } \\
\text { interactions } \\
\text { Three } \\
\text { components are } \\
\text { assessed: (i) } \\
\text { interdependency } \\
\text { among parts in } \\
\text { the system; (ii) } \\
\text { nonlinearity in } \\
\text { reasoning; and } \\
\text { (iii) emergent } \\
\text { patterns over } \\
\text { scale. }\end{array}$ & $\begin{array}{l}\text { Response indicates } \\
\text { that (i) the parts of } \\
\text { a system are } \\
\text { isolated with no } \\
\text { interdependency } \\
\text { among them; (ii) } \\
\text { the interactions } \\
\text { between parts are } \\
\text { linear with no } \\
\text { feedback; and (iii) } \\
\text { the patterns at the } \\
\text { system level are } \\
\text { the same from } \\
\text { those at the } \\
\text { component level. }\end{array}$ & $\begin{array}{l}\text { Response contains } \\
\text { one complex } \\
\text { component (out of } \\
\text { three) of } \\
\text { networked } \\
\text { interactions. (See } \\
\text { Level 4.) }\end{array}$ & $\begin{array}{l}\text { Response } \\
\text { contains two } \\
\text { complex } \\
\text { components (out } \\
\text { of three) of } \\
\text { networked } \\
\text { interactions. (See } \\
\text { Level } 4 \text {.) }\end{array}$ & $\begin{array}{l}\text { Response } \\
\text { indicates that (i) } \\
\text { the parts are } \\
\text { interdependent; } \\
\text { (ii) the } \\
\text { interactions } \\
\text { between parts are } \\
\text { non-linear with } \\
\text { feedback; and (iii) } \\
\text { the patterns at the } \\
\text { system level are } \\
\text { emergent. }\end{array}$ \\
\hline $\begin{array}{l}\text { Order } \\
\text { The focus is the } \\
\text { organization of } \\
\text { the system or } \\
\text { phenomenon - } \\
\text { centralized or } \\
\text { decentralized. }\end{array}$ & $\begin{array}{l}\text { Response indicates } \\
\text { that the system is } \\
\text { controlled by one } \\
\text { central agent, that } \\
\text { is, all action is } \\
\text { dictated by a } \\
\text { leader. Order in } \\
\text { the system is } \\
\text { established 'top- } \\
\text { down' or } \\
\text { determined with a } \\
\text { specific purpose in } \\
\text { mind. }\end{array}$ & $\begin{array}{l}\text { Response indicates } \\
\text { that the system is } \\
\text { largely controlled } \\
\text { by } 2-3 \text { central } \\
\text { agents, (i.e., there } \\
\text { are other parts that } \\
\text { may dictate how } \\
\text { the system } \\
\text { behaves). Order in } \\
\text { the system is } \\
\text { established 'top- } \\
\text { down.' }\end{array}$ & $\begin{array}{l}\text { Response } \\
\text { indicates that the } \\
\text { system is largely } \\
\text { decentralized } \\
\text { and the control } \\
\text { lies with } 4-5 \\
\text { components. } \\
\text { However, there is } \\
\text { little evidence to } \\
\text { show that the } \\
\text { order in the } \\
\text { system is self- } \\
\text { organized. }\end{array}$ & $\begin{array}{l}\text { Response } \\
\text { indicates that the } \\
\text { system is } \\
\text { decentralized and } \\
\text { control lies with a } \\
\text { myriad (more } \\
\text { than 5) of parts. } \\
\text { Order in the } \\
\text { system is self- } \\
\text { organized or } \\
\text { 'bottom-up', and } \\
\text { emerges } \\
\text { spontaneously. }\end{array}$ \\
\hline $\begin{array}{l}\text { Dynamic } \\
\text { processes } \\
\text { Processes refer } \\
\text { to the dynamism } \\
\text { of the } \\
\text { mechanisms that } \\
\text { underlie the } \\
\text { phenomena; in } \\
\text { other words, } \\
\text { how the system } \\
\text { works or is } \\
\text { thought to work. }\end{array}$ & $\begin{array}{l}\text { Response indicates } \\
\text { that the system is } \\
\text { composed of static } \\
\text { events. While } \\
\text { perturbations in } \\
\text { the system cause } \\
\text { change to occur, } \\
\text { the change } \\
\text { terminates once an } \\
\text { outcome is } \\
\text { achieved (i.e., a } \\
\text { definite end). }\end{array}$ & $\begin{array}{l}\text { Response indicates } \\
\text { that the system is } \\
\text { somewhat } \\
\text { composed of static } \\
\text { events with } \\
\text { suggestions that } \\
\text { these events take } \\
\text { time to reach the } \\
\text { outcome(s). }\end{array}$ & $\begin{array}{l}\text { Response } \\
\text { indicates that the } \\
\text { system is } \\
\text { somewhat of an } \\
\text { on-going process. } \\
\text { Perturbations } \\
\text { take a long time } \\
\text { to reach the final } \\
\text { outcomes, which } \\
\text { are at larger scale } \\
\text { than the initial } \\
\text { event(s). }\end{array}$ & $\begin{array}{l}\text { Response } \\
\text { indicates that the } \\
\text { system is an on- } \\
\text { going, dynamic } \\
\text { process. System } \\
\text { continues to be in } \\
\text { a state of flux. The } \\
\text { parts adapt or } \\
\text { evolve, and } \\
\text { continue to do so } \\
\text { accordingly. }\end{array}$ \\
\hline
\end{tabular}

Below is a sample student response that received Level 3 and 4 codes for all categories of complex systems ideas: 
Well if geese arrived it would probably help the ecosystem. The bird droppings might make the soil fertile. It would start to look a lot greener. The problem with that is erosion. The increase of plants and root size might cause paths or walkways to be damaged or destroyed. Statues might start to fall apart from the constant weight of birds. Plus, the increase of plants in amount and size make $\mathrm{O}_{2}$ levels higher. Which could cause a warm and wet ecosystem, much similar to a swamp. Over a long period of time of course. (Student response, March 2011)

In this sample, the student repeatedly used nondeterministic words, such as "might" and "could," and suggested three possible effects of the geese's arrival, which indicates his understanding of the unpredictable nature of the effects of the arrival of the geese (Level 3 deterministic effects). The student suggests that the geese can cause cascading effects on the soil, plant population, and oxygen levels, and might even lead to large-scale and long-term effects such as a "warm and wet ecosystem" (Level 4 scaling effects). More than four factors (e.g., droppings, soil, erosion, plants, oxygen) were identified as contributing to possible outcomes (Level 4 multiple causes). The response also hints at an understanding of the interdependence of the various components in the park ecosystem, the feedback mechanisms present in the system (i.e., paths or walkways damaged by more plants), and the possible emergence of a systemic pattern (i.e., warm and wet environment) (Level 4 networked interactions). In addition, the idea of decentralization is clearly demonstrated as four actors (i.e., geese, plants, soil, and oxygen) are said to be involved (Level 3 order). Furthermore, the response implies that the perturbations in the park ecosystem are somewhat ongoing, and might take a long time to arrive at a final state (Level 3 dynamic processes).

We coded the written responses for student understanding in each category of complex systems ideas. A breakdown of how their ideas scored is provided in Table 2. A simple frequency count shows that most of the responses were coded at a Level 2 (somewhat clockwork) or a Level 3 (somewhat complex) understanding of various complex systems ideas, with a smaller number showing a Level 4 (completely complex) understanding. We conducted a one-way ANOVA for each of the six categories of complex systems understanding to determine whether there were any statistically significant differences between scores the four grade levels. The results showed that there was no statistically significant difference. Thus, scores from all 44 students were pooled together to ensure a large enough sample size for the analysis that follows.

Because we were interested in determining the differences in conceptual difficulties among the six categories of complex systems ideas, and given that the analysis used successively ordered rating scales (i.e., four levels of understanding), a polytomous item response theory (IRT) model was the most appropriate procedure to assess responses (Keller, 2005). We used the generalized partial credit model (GPCM; Muraki, 1992), which is a two-parameter IRT model developed to analyze situations where responses contain more than two ordered items. The items, or categories in this case, are conceptualized as a series of hierarchical levels of performances, where respondents receive partial credit for successfully performing at a particular level.

\section{Results}


We rated the written responses for student understanding in each category of complex systems ideas. A breakdown of how they scored is given in Table 2. A frequency count shows that most of the responses were at a Level 2 (i.e., somewhat clockwork) or a Level 3 (i.e., somewhat complex) understanding of various complex systems ideas, with a smaller number showing a Level 4 (i.e., completely complex) understanding.

Table 2

Scoring for Each Category of Complex Systems Ideas by Grade Level

\begin{tabular}{|c|c|c|c|c|c|c|c|c|c|c|c|c|c|c|c|c|}
\hline \multirow{2}{*}{$\begin{array}{l}\text { Category } \\
\text { Grade }\end{array}$} & \multicolumn{4}{|c|}{ Level 1} & \multicolumn{4}{|c|}{ Level 2} & \multicolumn{4}{|c|}{ Level 3} & \multicolumn{4}{|c|}{ Level 4} \\
\hline & G & G & G & G & G & G & G & G & G & G & G & G & G & G & G & G \\
\hline & 8 & 9 & 10 & 12 & 8 & 9 & 10 & 12 & 8 & 9 & 10 & 12 & 8 & 9 & 10 & 12 \\
\hline Deterministic effects & 1 & 6 & 5 & 4 & 3 & 2 & 5 & 4 & 1 & 4 & 3 & 4 & 0 & 1 & 1 & 0 \\
\hline Scaling effects & 1 & 3 & 1 & 3 & 0 & 3 & 3 & 5 & 3 & 2 & 6 & 3 & 1 & 5 & 4 & 1 \\
\hline Multiple causes & 1 & 4 & 2 & 4 & 2 & 4 & 8 & 5 & 1 & 3 & 3 & 2 & 1 & 2 & 1 & 1 \\
\hline $\begin{array}{l}\text { Networked } \\
\text { interactions }\end{array}$ & 1 & 3 & 0 & 2 & 1 & 2 & 7 & 2 & 3 & 7 & 4 & 8 & 0 & 1 & 3 & 0 \\
\hline Dynamic processes & 1 & 5 & 2 & 3 & 4 & 4 & 8 & 7 & 0 & 3 & 3 & 1 & 0 & 1 & 1 & 1 \\
\hline Order & 1 & 3 & 4 & 7 & 2 & 4 & 8 & 2 & 2 & 5 & 2 & 3 & 0 & 1 & 0 & 0 \\
\hline Totals & \multicolumn{4}{|c|}{67} & \multicolumn{4}{|c|}{95} & \multicolumn{4}{|c|}{76} & \multicolumn{4}{|c|}{26} \\
\hline
\end{tabular}

We ran the GPCM on the 44 sets of scores, using PARSCALE 4.1. The model converged at a critical value equal to 0.005 , and had no items fit statistical significance, indicating a good model fit. The mean difficulty of the six items or categories was $0.49(S D=0.45)$, and the mean discrimination parameter was $1.10(S D=0.39)$. The categories were found to be reliable to measure students' understanding of complex systems (composite reliability $=0.87$ ). An examination of the total test information curve for the model indicated our test provided appropriate information for students with ability levels both below and above average (a continuum of ability level between -3 and +3 ). On this continuum of ability scale, 0 is set as the mean of the item difficulty parameter. On the positive direction toward +3 , each increase indicates that the item is more difficult; conversely, on the negative direction toward -3, each decrease indicates that the item is less difficult. The total test information peaked between 0 and 1, indicating that the categories could measure students with slightly higher than average abilities with the most precision. In addition, the model was able to show how well each item could distinguish students with different abilities by the discrimination parameter. The discrimination parameter typically ranges between 0.5 and 2.5 in value (Reeve \& Fayers, 2005). The larger this parameter, the more effective the item can distinguish students with varying levels of understanding.

Table 3 presents the six categories, their difficulty parameters, and their discrimination parameters. As indicated by the difficulty parameters, the categories of ideas found to be the most difficult to score in (higher difficulty scores) were: deterministic effects, order, and dynamic processes. The category of multiple causes was found to be at the intermediate level; and networked interaction and scaling effects categories were the easiest (lower difficult scores). All six categories could also distinguish students based on their abilities, as their discrimination parameters ranged from 0.69 
to 1.64. That is, the question is suitable for measuring the categories theorized. In addition, an examination of the test characteristic curves for this model indicated that the six items collectively provide adequate information for students with ability levels both below and above average.

Table 3

Generalized Partial Credit Model

\begin{tabular}{lcl}
\hline Category & Difficulty (SE) & Slope (SE) \\
\hline Scaling effects & $-0.17(.018)$ & $1.42(0.50)$ \\
Networked interaction & $0.04(0.22)$ & $1.64(0.58)$ \\
Multiple causes & $0.54(0.21)$ & $1.24(0.51)$ \\
Dynamic processes & $0.77(0.26)$ & $0.69(0.39)$ \\
Order & $0.86(0.22)$ & $0.72(0.98)$ \\
Deterministic effects & $0.87(0.29)$ & $0.91(0.34)$ \\
\hline
\end{tabular}

$N=44$.

The item difficulty parameters allowed us to order the six categories of complex ideas from easiest to hardest based on the 44 sets of responses. Items with a lower value on the item difficulty parameter suggests that students are more likely to understand the concept. Conversely, items with a higher value on the item difficulty parameter suggests that students are less likely to understand the concept. If we assume that differences in item difficulty correspond to differences in levels of sophistication in the ways that students reason and learn about various complex system ideas, then the results may suggest a learning progression, moving from less to more sophisticated understanding of complex systems concepts. Table 4 provides details about what a learning progression along the difficulty continuum might look like with corresponding student examples in each category.

Table 4

Suggested Learning Progression with Student Examples

\section{Complex Suggested Learning Progression with Student Reasoning Systems Examples \\ Category}

Scaling effects The geese may chase off other animals, which could stop them from eating plants they normally eat, which causes the population of these plants to increase. An increase of other animals that feed on these plants may then occur as they have more to eat. [cascading effect]. There may be overpopulation of the geese as they lack the natural predators [large scale].

Networked The geese will probably help the ecosystem. First, their droppings might interaction make the soil more fertile, and plants will grow better [nonlinear]. There 
may be more $\mathrm{O}_{2}$ as a result [interdependency]. The result of $\mathrm{O}_{2}$ and plant increase could cause a wet and warm ecosystem. [emergent patterns].

Multiple causes $\begin{aligned} & \text { The geese may also eat most of the grass [cause]. The caterpillars and other } \\ & \text { grass eaters will die or move to another ecosystem [effect/cause]. This } \\ & \text { would mean that the decomposers will have less to eat [effect/cause]. The } \\ & \text { soil may have fewer nutrients as a result, and the trees will grow less well } \\ & \text { [cause/effect]. The geese may also damage statues and walkways with their } \\ & \text { droppings [cause/effect]. }\end{aligned}$
Dynamic
processes $\begin{aligned} & \text { The geese may increase the competition for the same food with other } \\ & \text { animals. The other animals may leave the park to seek greener pastures. } \\ & \text { However, over time, with more geese in the park, the amount of nutrients } \\ & \text { in the soil is likely to increase as there are more decaying matter (feces and } \\ & \text { dead geese). This allows the park to support more producers and } \\ & \text { consumers. At the same time, overcrowding may occur. The lack of space } \\ & \text { may again decrease the populations. This process will continue on until a } \\ & \text { new equilibrium can be reached or the cycle can carry on indefinitely } \\ & \text { [continual changes]. }\end{aligned}$

Order Geese may have both positive and negative effects on the ecosystem. For example, they [a central actor] may decrease the amount of food available to other animals who preyed on the same type of food as the geese. The geese may also increase the amount of food available to animals who can eat the geese. The effects of geese on the ecosystem cannot be easily determined without considering the other animals and plants in the same ecosystem as well [while only one actor is explained, it shows evidence of decentralization in understanding].

Deterministic effects
Since the geese arrive at a place they haven't ever been before, there are many ways they can affect the ecosystem and it is impossible to say exactly how [uncertainty in tone]. For example, they could drive other birds away so that they can lay eggs [ $1^{\text {st }}$ alternative]. They could drive other birds away because they compete for the same kind of food [ $2^{\text {nd }}$ alternative]. They could cause the increase of other animals [ $3^{\text {rd }}$ alternative] who feed on geese. They could cause the increase of other birds [ $4^{\text {th }}$ alternative] because the geese have become an alternative food source for existing predators. It's really hard to tell [suggestions of complete unpredictability].

The student examples indicate a Level 4 understanding where responses at this level existed in the data. In cases where only Level 3 responses existed, we added more information to those examples to make it a Level 4 response. Beginning with the easiest category of scaling effects, students understand that other variables in the park would be affected with the addition of the geese in the park ecosystem. The next level, networked interactions, entails understanding that the interactions between the geese and the other variables could cause emergent changes due to $2^{\text {nd }}$ order connections in the network and the interdependencies between the connections. In the 
following category of multiple causes, students become aware of the multiple causes and effects that can contribute to these emergent changes. In the category of dynamic processes, students understand that these emergent changes continually happen over time and that fluctuations in variable populations will occur. In the next most challenging category of order, students realize that ecosystem changes happen because systems have decentralized organization, that is, the locus of control is spread across the multiple interconnected and interdependent variables. Finally, in the most challenging category, deterministic effects, students understand that it is hard to predict what would happen in the park ecosystem with the addition of the geese because of all the characteristics of complex systems instantiated in the previous categories, and that the emergent changes would need to be observed over time.

\section{Discussion}

Previous research on student understanding of complex systems has mainly explored isolated or incomplete processes or structures. Our study explored what students find more or less challenging to understand about complex systems, in line with new science education standards that call for a more systematic organization of knowledge (NRC, 2012). We have proposed that learning progressions research can help to systematize the learning pathways students take to improve conceptual competence in complex systems. These learning pathways can in turn guide the curriculum and instructional activities in promoting complex systems learning, which is our ultimate goal.

As there was sparse literature to guide us in hypothesizing such a sequence, we adopted an inductive approach in constructing the progression similar to Mohan et al.'s study (2009). Using the GPCM, we analyzed 44 students' written responses to a biology question concerning the effects of the arrival of geese on a park ecosystem, with the aim of assessing the students' understanding of various complexity ideas. We acknowledge the small sample size in this exploratory study and the implication this has on the generalizability of claims. But we believe that the findings are an important initial step to describing a learning sequence from which to undertake more robust research.

We found that two of the easiest categories of ideas for students to comprehend are those that relate to the effects of actions in complex systems (scaling effects) and the interconnected and emergent nature of these systems (networked interactions). A "completely complex" understanding of these ideas includes the ability to reason that small actions can lead to large effects; that these actions can produce both localized and cascading changes; that the changes can occur immediately and over a long period of time; that the parts in the system are interdependent; that the relationships among the parts in the system are nonlinear with feedback mechanisms; and that the parts interact to produce emergent patterns that are not obvious at the component level. Students seem to experience more difficulty in interpreting that there are multiple causes that may contribute to the outcome(s) of a change (multiple causes), and perceiving that the system continues to undergo adaptation or evolution (dynamic processes). The categories of complex systems ideas that appear to be the most challenging to understand are order and deterministic effects; these complexity ideas concern the decentralized organization of the system, and the predictability of the effects caused by the variables of the system. 
Within the context of our test question, this ordered sequence of complexity ideas is valid. In a question that frames the complexity within an ecosystem of a park located in the students' own city, the students might have found it easier to visualize the manifestation of complexity ideas associated with the interconnectedness and interdependency of the various plant and animal species in the park, as well as the cascading, emergent, and nonlinear effects the arrival of the geese might have on the rest of the ecosystem (i.e., the scaling effects and networked interactions categories). In contrast, complexity ideas in the order and deterministic effects categories are less "visible" (such as the decentralized nature of interactions after the geese created the initial perturbation); in other words, the notion that there are myriad other components (e.g., plants, predators, and prey to geese, climate) that may contribute to how the system is organized, and that it is not possible to predict with precision the effects of the arrival of the geese at the park, could fall well outside of students' perceptual abilities. Chi (2005) provides another possible explanation, proposing that some scientific concepts and ideas may be easier to comprehend because of the ontological categories they belong to. Chi explains that "ontological categories refer to the basic categories of realities or the kinds of existence in the world, such as concrete objects, events, and abstractions" (p. 163). The more visible ideas of complex systems may represent ontologically easier categories for students to understand.

Our findings align well with current literature on students' understandings of complex systems while also advancing the field by establishing an initial progression of the various ideas associated with complex systems. Previous studies have highlighted challenges in learning about only one or a few complex systems concepts and our results with respect to those concepts agree with other study findings. For example, research (e.g., Levy \& Wilensky, 2009; Taber \& GarciaFranco, 2010; Wilensky \& Reisman, 2006; Jacobson et al., 2011) has shown that students tend to believe that complex systems are deterministic and centrally controlled. Likewise, researchers have observed that students tend to think linearly about relationships among the components (Gotwals \& Songer, 2010; Hogan, 2000; Riess \& Mischo, 2010; Sweeney \& Sterman, 2007), have difficulty understanding emergent patterns that result from multiple causes (Chi et al., 2012; Grotzer, 2015), and do not adequately articulate an understanding of the multiple variables and their interrelatedness within the system as a whole (Ben-Zvi Assaraf \& Orion, 2010). Collectively, this research has shown that when students are exposed to appropriate instruction, learning challenges can be overcome in these individual areas of complex systems learning.

The results of our study also corroborate results found in studies that reveal difficulty levels with a portion of complex systems ideas. For example, Hmelo-Silver and colleagues have consistently found that the structural components of systems (e.g., which parts or features are important to include in particular systems) are more easily identified than processes or behaviors like feedback loops (Hmelo et al., 2000; Hmelo-Silver et al., 2004; 2007). In their hierarchical model of complex systems understanding, Ben-Zvi Assaraf and colleagues have shown that components, and then relationships, and then hidden processes that enable systems to evolve, comprise the hierarchy of learning difficulties from the least challenging to the most (Ben-Zvi Assaraf et al., 2005; 2010). In our suggested order of easiest to most difficult concepts to learn, the scaling, networked, and multiple causes categories, generally align with the categories of structures and components. Whereas the latter categories of dynamic processes, order, and deterministic effects, generally align with relationships and hidden processes. Our progression also roughly supports 
the ordering of content in the cross-cutting concept of systems and system models found in the NGSS. In the earlier grades, the standards emphasize components and their interactions, while in the upper grades, the focus is on system processes and the prediction of evolved system behaviors. The added value of our suggested learning progression over other conceptions of relative developmental comparisons, is that it specifies particular structures (e.g., networks), behaviors (e.g., multiple causal factors), and processes (e.g., decentralized control) that teachers can apply in instruction.

Here we conclude with an instructional sequence from the least to the most challenging concepts to comprehend for middle and high school students (who were the participants in our study). In the middle grades, the focus could be on identifying different variables and levels of a system and how they are connected (e.g., predator-prey interactions). Early high school students could build on this knowledge by learning about how system organization changes and depends on multiple ongoing causes (e.g., why and how predator-prey populations fluctuate over time). Finally, upper high school students could further develop their complex systems competency by investigating the decentralized probabilistic nature of scientific phenomenon (e.g., how random variation in a population could lead to shifts in states of equilibrium). Importantly, these levels or concepts within the learning progression need to be articulated in instruction as processes and structures that comprise a whole system.

In subsequent studies we aim to further validate the progression with a larger sample size and apply it to other scientific domains such as physics and chemistry in order to determine how robust it is as a general complex systems heuristic.

\section{References}

Alonzo, C. A., \& Gotwals, A. W. (2012). Learning progressions in science: Current challenges and future directions. The Netherlands: Sense Publishers.

Alonzo, A., \& Steedle, J. (2008). Developing and assessing a force and motion learning progression. Science Education, 93, 389-421.

Ben-Zvi Assaraf, O., \& Orion, N. (2005). Development of system thinking skills in the context of earth system education. Journal of Research in Science Teaching, 42(5), 518-560.

Ben-Zvi Assaraf, O., \& Orion, N. (2010). System thinking skills at the elementary school level. Journal of Research in Science Teaching, 47(5), 540-563.

Ben-Zvi Assaraf, O., \& Orpaz, I. (2010). The "Life at the Poles" study unit: Developing junior high school students' ability to recognize the relations between earth systems. Research in Science Education, 40, 525-549.

Chi, M. T. H. (2005). Commonsense conceptions of emergent processes: Why some misconceptions are robust. The Journal of the Learning Sciences, 14(2), 161-199.

Chi, M. T. H., Roscoe, R., Slotta, J., Roy, M., \& Chase, M. (2012). Misconceived causal explanations for "emergent" processes. Cognitive Science, 36, 1-61.

Consortium for Policy Research in Education. (2009). Learning progressions in science: An evidence-based approach to reform (CPRE Research Report \# RR-63). New York: Teachers College Columbia University. Retrieved from http://www.cpre.org/images/stories/cpre_pdfs/lp_science_rr63.pdf on August 20th, 2010.

Gotwals, A. W., \& Songer, N. B. (2010). Reasoning and down a food chain: Using an assessment framework to investigate students' middle knowledge. Science Education, 94, 259-281.

Grotzer, T., \& Basca, B., (2003). How does grasping the underlying causal structures of ecosystems impact students' understanding? Journal of Biological Education, 38(1), 16-29.

Grotzer, T. A., Power, M. M., Derbiszewska, K. M., Courter, C. J., Kamarainen, A. M., Metcalf, S. J., \& Dede, C. (2015). Turning transfer inside out: The affordances of virtual worlds and mobile devices in real world 
contexts to teaching about causality across time and distance in ecosystems. Technology, Knowledge and Learning, 20, 43-69.

Grotzer, T. A., \& Tutwiler, M. S. (2014). Simplifying causal complexity: How interactions between modes of causal induction and information availability lead to heuristic-driven reasoning. Mind, Brain, and Education, 8(3), 97-114.

Hmelo-Silver, C. E., \& Azevedo, R. (2006). Understanding complex systems: Some core challenges. The Journal of the Learning Sciences, 15(1), 53-61.

Hmelo, C. E., Holton, D., \& Kolodner, J. L. (2000). Designing to learn about complex systems. The Journal of the Learning Sciences, 9, 247-298.

Hmelo-Silver, C. E., Marathe, S., \& Liu, L. (2007). Fish swim, rocks sit, and lungs breathe: Expert-novice understanding of complex systems. Journal of the Learning Sciences, 16(3), 307-331.

Hmelo-Silver, C. E., \& Pfeffer, M. G. (2004). Comparing expert and novice understanding of a complex system from the perspective of structures, behaviors, and functions. Cognitive Science, 28, 127-138.

Hogan, K. (2000). Assessing students' systems reasoning in ecology. Journal of Biological Education, 35(1), 22-28.

Jacobson, M. (2001). Problem solving, cognition, and complex systems: Differences between experts and novices. Complexity, 6(3), 41-49.

Jacobson, M. J., Kapur, M., So, H. J., \& Lee, J. (2011). The ontologies of complexity and learning about complex systems. Instructional Science, 39, 763-783.

Jacobson, M. J., \& Wilensky, U. (2006). Complex systems in education: Scientific and educational importance and implications for the learning sciences. The Journal of the Learning Sciences, 15(1), 11-34.

Keller, L. A. (2005). Item response theory (IRT) models for polytomous response data. In: B. S. Everitt \& D. D. Howell (Eds.), Encyclopedia of Statistics in Behavioral Sciences (p. 990-1003). Chichester: John Wiley \& Sons.

Klopfer, E., Scheintaub, H., Huang, W., Wendel, D., \& Roque, R. (2009). The simulation cycle: combining games, simulations, engineering and science using StarLogo TNG. E-Learning, 6(1), 71-96.

Levy, S. T., \& Wilensky, U. (2009). Students' learning with the connected chemistry (CCI) curriculum: Navigating the complexities of the particulate world. Journal of Science Education and Technology, 18, 243254.

Levy, S. T., \& Wilensky, U. (2011). Mining students' inquiry actions for understanding of complex systems. Computers \& Education, 56, 556-573.

Mohan, L., Chen, J., \& Anderson, C. W. (2009). Developing a multi-year learning progression for carbon cycling in socio-ecological systems. Journal of Research in Science Teaching, 46(6), 675-698.

Muraki, E. (1992). A generalized partial credit model: Application of an EM algorithm. Applied Psychological Measurement, 16, 159-176.

National Research Council, NRC (2007). Generating and evaluating scientific evidence and explanation. In R. Duschl, H. Schweingruber, \& A. Shouse (Eds.), Taking science to school: Learning and teaching science in grades K-8 (pp. 129-167). Washington D.C.: National Academies Press.

National Research Council. (2012). A framework for K-12 science education: Practices, crosscutting concepts, and core ideas. Washington, DC: National Academies Press.

National Science Foundation. (2011). Empowering the nation through discovery and innovation-NSF strategic plan for fiscal years (FY) 2011-2016. Arlington, VA: National Science Foundation.

Penner, D. E. (2000). Explaining systems: Investigating middle school students' understanding of emergent phenomena. Journal of Research in Science Teaching, 37(8), 784-806.

Program for International Student Assessment. (2006). PISA Released Items-Science. Paris: OECD. Retrieved from http://www.oecd.org/dataoecd/13/33/38709385.pdf on Oct. 14, 2011.

Resnick, M. (1996). Beyond the centralized mindset. Journal of the Learning Sciences, 5, 1-22.

Reeve, B., \& Fayers, P. (2005). Applying item response theory modeling for evaluating questionnaire item and scale properties. In: P. Fayers \& R. Hays (Eds.), Assessing quality of life in clinical trials: Methods and practice (2nd Ed., p. 55-74). Oxford: Oxford University Press.

Riess, W., \& Mischo, C. (2010). Promoting systems thinking through biology lessons. International Journal of Science Education, 32(6), 705-725. 
Sewell, A. (2002). Constructivism and student misconceptions. Why every teacher needs to know about them. Australian Science Teachers Journal, 48(4), 24-28.

Shavelson, R. J., \& Kurpius, A. (2012). Reflections on learning progressions. In, A. C. Alonzo and A. W. Gowals (Eds.) Learning progressions in science: Current challenges and future directions (pp. 13-26). The Netherlands: Sense Publishers.

Songer, N. B., Kelcey, B., \& Gotwals, A. W. (2009). How and when does complex reasoning occur? Empirically driven development of a learning progression focused on complex reasoning about biodiversity. Journal of Research in Science Teaching, 46(6), 610-631.

Sweeney, L., \& Sterman, J. (2007). Thinking about systems: student and teacher conceptions of natural and social systems. System Dynamics Review, 23(2/3), 285-312.

Taber, K. S., \& García Franco, A. (2010). Learning processes in chemistry: Drawing upon cognitive resources to learn about the particulate structure of matter. Journal of the Learning Sciences, 19(1), 99-142.

Wilkerson-Jerde, M. H., \& Wilensky, U. J. (2015). Patterns, probabilities, and people: Making sense of quantitative change in complex systems. Journal of the Learning Sciences, 24(2), 204-251.

Wilenksy, U., \& Rand, W. (2015). An introduction to agent-based modeling. Modeling natural, social and engineered complex systems in NetLogo. Cambridge MA: MIT Press.

Wilensky, U., \& Reisman, K. (2006). Thinking like a wolf, a sheep, or a firefly: Learning biology through constructing and testing computational theories-an embodied modeling approach. Cognition and Instruction, 24(2), 171-209.

Wilensky, U., \& Resnick, M. (1999). Thinking in levels: A dynamic systems approach to making sense of the world. Journal of Science Education and Technology, 8(1), 3-19.

Yoon, S. (2008). An evolutionary approach to harnessing complex systems thinking in the science and technology classroom. International Journal of Science Education, 30(1), 1-32.

Yoon, S. A. (2011). Using social network graphs as visualization tools to influence peer selection decisionmaking strategies to access information about complex socioscientific issues. Journal of the Learning Sciences, 20(4), 549-588.

Yoon, S., Goh, S., Park, M. (2018). Teaching and learning about complex systems in K-12 science education: A review of empirical studies 1995-2015. Review of Educational Research, 88(2), 285-325.

\section{Acknowledgments}

This research was funded by a grant from the U.S. National Science Foundation, \#1019228.

\section{About the Author/s}

Susan A. Yoon, Ph.D., is Professor of Education in the Teaching, Learning, and Leadership Division at the Graduate School of Education of the University of Pennsylvania. Her research interests in the areas of the learning sciences and science education examine how visualization tools and curricula can support the learning of complex scientific phenomena. She has investigated student learning impacts and teacher professional development structures including building social networks and social capital to support instructional practices and learning. Correspondence: yoonsa@upenn.edu.

Sao-Ee Goh, Ph.D., is a researcher with the Academy of Singapore Teachers with the Ministry of Education in Singapore. His research interests include professional development and science education. Correspondence: sedm0253@yahoo.com.

Zhitong Yang, is a research project manager at the Center for Academic and Workplace Readiness and Success at Educational Testing Service. He manages multiple projects focusing on design and implementation of innovative assessment tools to measure cognitive bias, personality, collaborative problem solving, and job performance. His research interests include assessment of science content, noncognitive traits and skills, and 
collaborative learning. He is completing his doctorate at the Graduate School of Education of the University of Pennsylvania. Correspondence: zhitongy@gmail.com.

(C) Copyright 2019. The authors, SUSAN YOON, SAO-EE GOH, and ZHITONG YANG, assign to the University of Alberta and other educational and non-profit institutions a non-exclusive license to use this document for personal use and in courses of instruction provided that the article is used in full and this copyright statement is reproduced. The authors also grant a non-exclusive license to the University of Alberta to publish this document in full on the World Wide Web, and for the document to be published on mirrors on the World Wide Web. Any other usage is prohibited without the express permission of the authors. 